\title{
Scale effect on electrical characteristics of CPC-PV
}

Guiqiang Lia ${ }^{\mathrm{a}, *}$ Guiqiang.Li@hull.ac.uk, Yashun Lu ${ }^{\mathrm{b}}$, Samson Shittu ${ }^{\mathrm{a}}$, Xudong Zhao ${ }^{\mathrm{a}, \mathrm{c}}$

${ }^{a}$ Research Centre for Sustainable Energy Technologies, University of Hull, Hull, HU67RX, UK

${ }^{\mathbf{b}}$ Department of Thermal Science and Energy Engineering, University of Science and Technology of China, 96 Jinzhai Road, Hefei City, 230026, China

'Department of Power Engineering, North China Electric and Power University, Baoding, Hebei, 071003, China

${ }^{*}$ Corresponding author.

\begin{abstract}
Recently, the flux distribution and Photovoltaic (PV) structure optimization have been paid more attention in the design of concentrating Photovoltaic (CPV) by several researchers while the scale factor is sometimes decided by the processing technology used and cost. However, the same CPV devices with the same concentration ratio under different scales may possess different electrical characteristics. Therefore, this paper presents a comparison of two different scales of compound parabolic concentrating (CPC) PV with the same concentration ratio of $4 \mathrm{X}$, based on the commercial crystalline silicon solar cell. The model is verified by experiment firstly, then the electrical characteristics comparison is performed. The results show that the maximum output power of small-scale CPC-PV cells is $424.960 \mathrm{~mW}$, which is significantly higher than the maximum output power of large-scale CPC-PV cells of $420.713 \mathrm{~mW}$. This means that the small scale one has a better electrical performance than the large scale one in this situation thus, this study will provide a reference for future CPC-PV design.
\end{abstract}

Keywords: CPC; Concentrating photovoltaic; Electrical characteristics; Scale factor; Illumination intensity

\section{Introduction}

The reality of climate change has been confirmed by the increased frequency of extreme weather conditions around the world thus, there is an urgent need for alternative sources of energy instead of the conventional sources like fossil fuel that cause the environmental issues $[1,2]$. The most potent energy source in the world is the sun which is also a renewable energy source [3]. Consequently, solar energy is one of the most attractive energy sources with a very minimal negative environmental impact [4]. Solar photovoltaics can be used to 
generate electricity directly from the incident solar radiations thus, it is currently a mature technology due to its advantages such as zero pollution, silent operation, low maintenance and high reliability. In addition, the use of photovoltaic (PV) is increasing speedily due to the fact that the demand for electrical power is growing exponentially therefore, the pressure on existing grids to deliver stable and sustainable electricity is increasing [5].

Solar concentrating photovoltaic (CPV) is one of the typical applications of photovoltaic in which solar radiations is concentrated on PV cells including the commercial silicon solar cell, the triple-junction solar cell and the perovskites solar cell etc. [6,7]. Usually, solar radiation is focused by mirrors or lenses onto a small array of PV cells in an effort to increase the input heat flux and overall efficiency of the cells. The CPV system has attracted a great attention as it possesses the highest efficiency of all PV technologies [8,9]. Commercial crystalline silicon solar cell which makes up almost $90 \%$ of the worldwide solar cell market [10], has several advantages compared to other kinds of solar cells such as: non-toxic, high stability, relatively low cost and high efficiency [11]. In addition, for low concentration PV systems, the crystalline silicon solar cell may be a good choice due to the unique advantages it offers.

Sun et al. [12] proposed a linear CPV system with direct liquid-immersion cooling of mono-crystalline solar cells using dimethyl silicon oil. Their experimental results showed that the liquid-immersion cooling capacity in their designed receiver was favorable and the electrical performance of the cells immersed in the silicon oil was stable. Poulek et al. [13] designed a new self-powered low concentration PV solar tracker using bifacial solar cells. The authors argued that their design did not need additional power supply or cables thus, the cost was reduced compared to classical PV power plants. Similarly, Amanlou et al. [14] investigated the effects of applying the linear Fresnel concentrator and new designed diffuser on the uniformity of the PV temperature distribution. The results obtained showed that their new design improved the electrical efficiency of the PV/T collector by $20 \%$. Furthermore, Nilsson et al. [15] performed a long term evaluation of an asymmetric CPC PV thermal hybrid system. The results obtained showed that the optimal position to place the PV cells was facing the front reflector while having cells on both sides is the best option in most cases.

Compound parabolic concentrator (CPC) as a typical solar concentrator, is often used in the low concentration PV system. In fact, CPC is an attractive solution as a low concentration concentrator with a larger acceptance angel and without a tracking requirement therefore, it can improve the performance of the system and reduce the cost of PV system, solar thermal system, daylighting and lighting systems amongst others [16,17]. Lu et al. [18] designed and developed an asymmetric compound parabolic photovoltaic concentrator for building façade. Their experimental results showed their developed building façade integrated asymmetric compound parabolic photovoltaic concentrator increased the power output per unit solar cell area by a factor of 2 compared to non-concentrating PV system. Similarly, Sabry et al. [19] presented a low concentration façade integrated PV system which was made from transparent acrylic CPC segments and the authors argued that reducing side area of the CPC segments was a tradeoff between electricity generated and solar radiation transmitted through the window. Li et al. [20] performed a numerical and lab experimental study of a novel concentrating PV with uniform flux distribution. The authors used a two-dimensional finite element model to study the electrical performance of the concentrating PV and an indoor lab experiment was performed to validate the model. Results obtained showed that the proposed concentrator enhanced the PV output under 
concentrating illumination due to the uniform flux distribution. Furthermore, Hatwaambo et al. [21] investigated the performance of a low-concentrator PV system with two highly specular materials (miro and anodized aluminum) and a diffuse material with rolling marks (rolled aluminum foil) used as reflective elements. They found that the ray-tracing and short circuit current results were similar within $10 \%$ but different from spectrophotometer measured results.

Liu et al. [22] presented a novel compound parabolic concentrating photovoltaic/thermal (PV/T) collector with microencapsulated phase change slurry. A three-dimensional numerical model was used to analyze the dynamic performance of the PV/T collector and the authors found that the microencapsulated phase change slurry enhanced the thermal and electrical efficiency by $9.24 \%$ and $1.8 \%$ respectively. Similarly, Proell et al. [ 23 ] performed an experimental study of a low concentrating CPC PV/T flat plate collector and the thermal and PV efficiency were measured using maximum power point tracking (MPPT). Results showed that the thermal efficiency was enhanced by $34 \%$ compared to that of a glazed flat plate PV/T which was $17 \%$ for collector temperatures $60 \mathrm{~K}$ over ambient temperature. Xuan et al. [24] presented a novel asymmetric lens-walled CPC which was integrated into a building south wall and a special rotation angle was introduced at the bottom so as to optimize the performance of the system. In addition, ray tracing simulation was performed to validate the experimental results which showed that the asymmetric lens-walled CPC increased the maximum power by a ratio of $1.74 \mathrm{x}$ compared to the bare cell. In addition, Bahaidarah et al. [25] presented a comparative study on the effect of glazing and cooling for CPC PV systems. A theoretical model was developed by the authors and used to evaluate the electrical and thermal performance of the CPC PV system. They found that the glazing increased the thermal performance of the CPC PV system while the unglazed CPC PV system provided a greater electrical power output. Additionally, the same authors performed another comparative study on a flat PV string and symmetric CPC PV system. Results obtained showed that the power output of the CPC PV system was higher than that of the flat PV string with and without cooling by $39 \%$ and $23 \%$ respectively [26]. Another experimental study was performed by Li et al. [27] on the flux distribution of lens-walled compound parabolic concentrator (CPC) compared to mirror CPC. The experimental and simulation results were all in agreement and showed that the lens-walled CPC performed better than the mirror CPC.

In fact, the current CPC-PV can also be divided into large scale [23,28,29] and small scale [20,30,31]. The large ones can be convenient to control and operate while the small ones can be easy to process because of the miniature structure. Even though these CPV systems have the same concentration ratio, they have different solar cell scales. Especially, in many CPC-PV systems with the large scale, the solar cells are still made up of many small solar cells units, so the flux distribution on the top surfaces of these solar cells are different from those of the solar cells with the small scales. In addition, for the large-scale ones, the arrangement and combination of the PV cells is different from that of the small scale. Therefore, for the same concentration ratio, the CPC-PV systems with different scales may have different electrical output performance. Current studies tend to focus on the CPC structure optimization and the selection of the geometrical concentrating ratio, as well as the matching between the CPC and the PV. However, there are few studies which pay attention on the scale effect on electrical characteristics of CPC-PV with the same geometrical concentrating ratio.

Therefore, this paper focuses on the investigation of the electrical characteristics of different scale CPC-PV modules. Two CPC-PV modules with the same concentration ratio of $4 \mathrm{X}$ under different scales are compared. 
Then the model is verified by the experiment. Detailed comparison of the current density distribution is also conducted. In addition, the discussion on the electrical characteristics of the two types CPC-PV modules is also presented, which shows the different characteristics of different scale CPC-PV modules. The rest of the paper is organized as follows: Section 2 presents the model description, Section 3 shows the model validation, Section 4 presents the results and subsequent discussion while Section 5 describes the main conclusions drawn from this study.

\section{Model description}

\subsection{The CPC-PV cell module}

The two different scales CPC-PV cell with the same geometric concentration ratio are shown in Fig. 1. Among them, Fig. 1(a) is a CPC-PV cell module with a geometric concentration ratio of 4X. The CPC-PV cell module is mainly composed of two symmetrical mirrors and a crystalline silicon cell having a size of $15 \times 70 \mathrm{~mm}^{2}$. The whole crystalline silicon cell consists of 5 unbroken and 3 segmental emitter regions, 6 fingers in crystalline silicon cell width direction and 1 finger in crystalline silicon cell length direction and 1 bus-bar. The internal current of the CPC-PV cell is derived from the bus-bar.

alt-text: Fig. 1

Fig. 1 

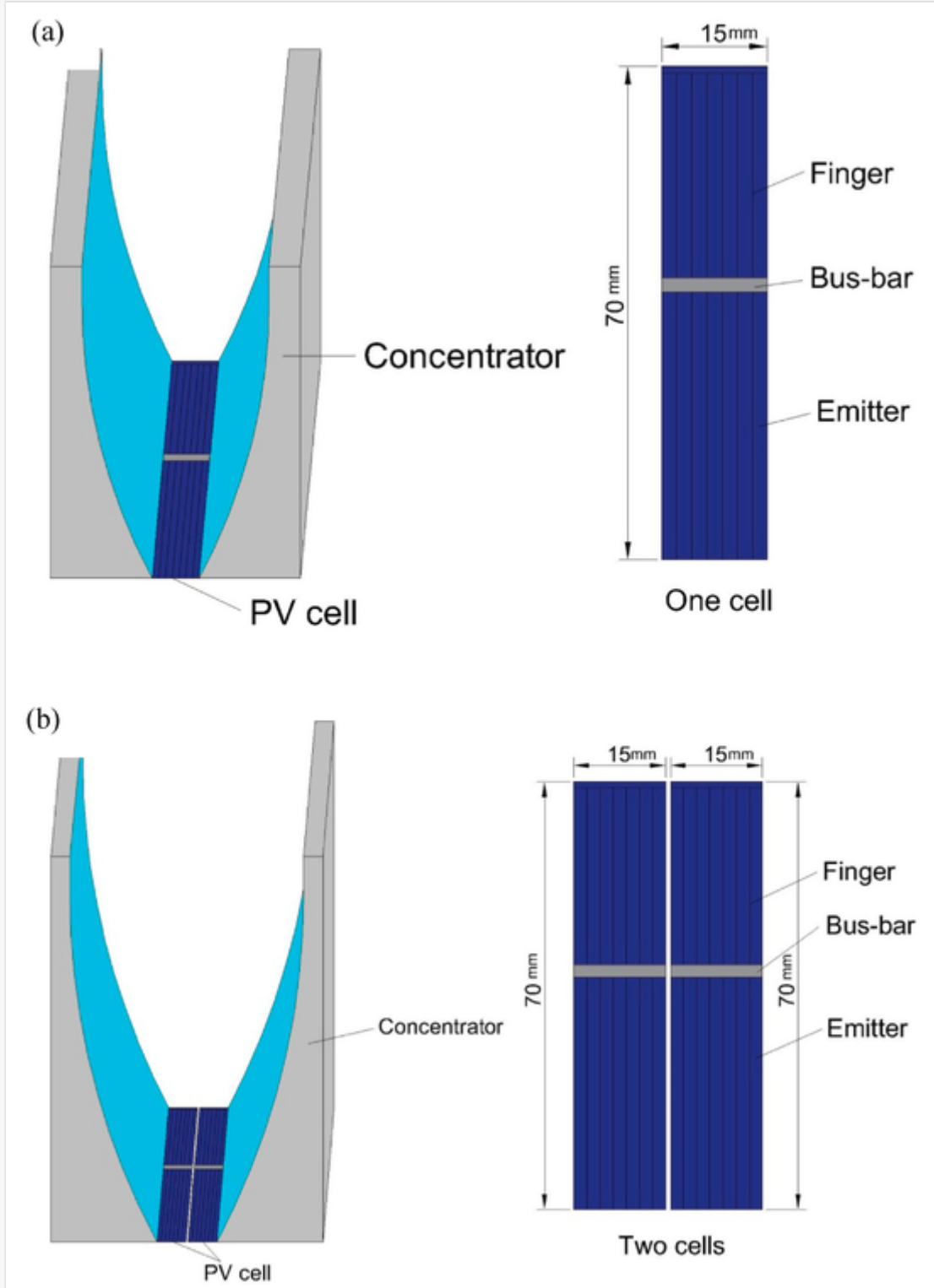

Two different scales CPC-PV cell with the same geometric concentration ratio: (a) the small-scale CPC-PV cell module; (b) the large-scale CPC-PV cell module.

Fig. 1(b) is also a CPC-PV cell module with a geometric concentration ratio of $4 \mathrm{X}$. The CPC-PV cell module is mainly composed of two symmetrical mirrors and two crystalline silicon cells with a size of $30 \times 70 \mathrm{~mm}^{2}$. Each of the two crystalline silicon cells is identical to the crystalline silicon cell of Fig. 1(a). It can be seen from Fig. 1(b) that the entire CPC-PV cell module is composed of two identical small CPC-PV cell modules.

The geometrical scale of the CPC-PV cell module in Fig. 1(b) is twice than that of the CPC-PV cell module in Fig. 1(a), and the geometric concentration ratio of the two CPC-PV cell modules is the same. In this paper, the comparison of the electrical performance of two CPC-PV cell modules with the same geometrical concentration ratio but different geometrical scale is illustrated. For the convenience of the description in the paper, the CPC-PV cell modules in Fig. 1(a) and (b) are described as the small-scale CPC-PV cell module and the large-scale CPC-PV cell module respectively. In order to compare them clearly, the half of the large-scale 
CPC-PV cell module (one cell) was chosen since it can obtain the average illumination intensity and the geometrical size as the same as those in the small-scale CPC-PV.

\subsection{Model domain}

The whole crystalline silicon cell in a CPC-PV cell module can be considered as consisting of many identical finger elements as shown in Fig. 2. The cell element can be selected as the domain for simulation. However, simulating the whole cell emitter instead of the cell element has the advantage that the same domain is reproduced, and thus can be used to check for any anomalies in numerical methods, especially around the troublesome edge regions [32]. Since the total illumination intensity of a single crystalline silicon cell in the two different scales CPC-PV cell modules shown in Fig. 1 is the same, a finite element simulation of a single crystalline silicon cell based on the measured data can be performed.

alt-text: Fig. 2

\section{Fig. 2}

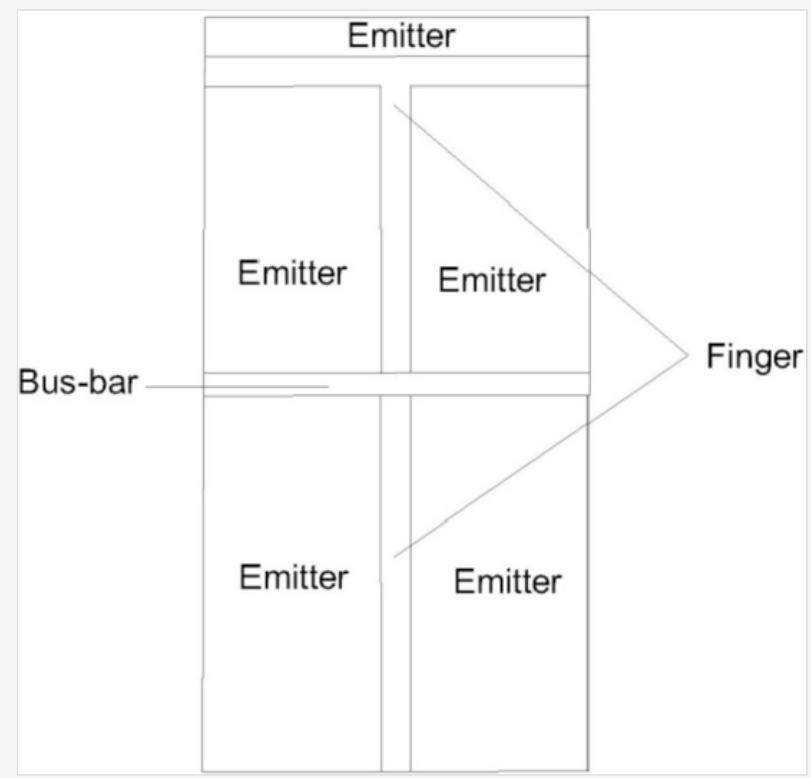

The cell element to be modelled.

\subsection{Illumination profile}

A three-dimensional plot of the illumination intensity distribution of the two different scales CPC-PV cell modules is shown in Fig. 3. It is worth noting that in this paper, the non-uniform illumination intensity distribution of the two different scales CPC-PV cell modules is only considered in the lateral direction of the CPC-PV cell due to the symmetrical mirror surface on the left and right sides. The non-uniformity of the smaller illumination intensity in the vertical direction of the CPC-PV cell caused by other possible factors is not considered in this paper. 
(a)

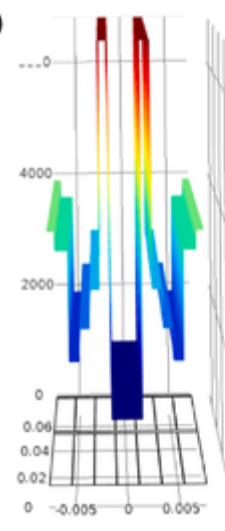

(b)

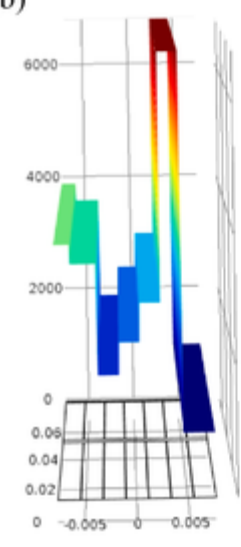

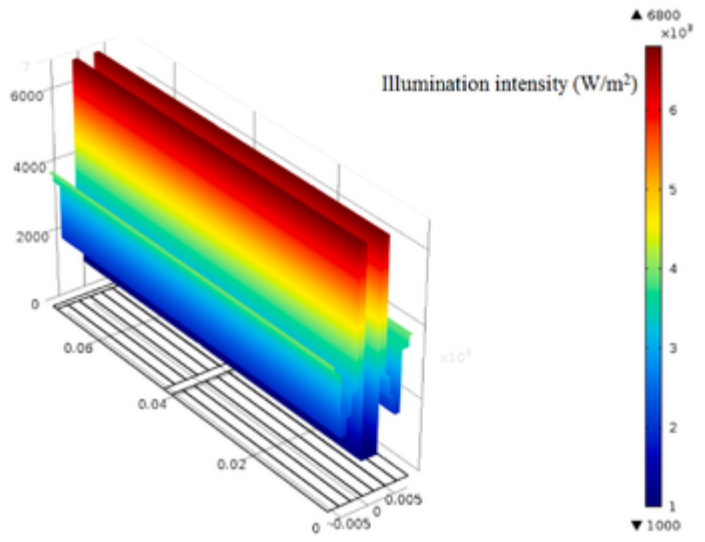

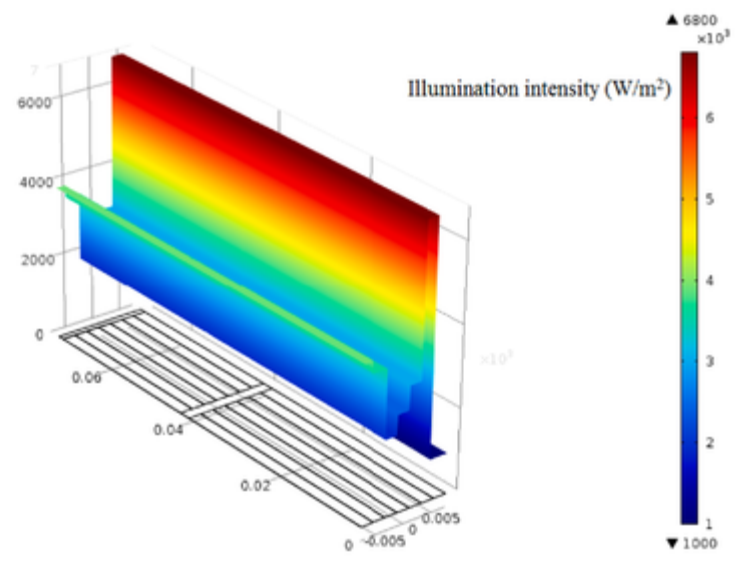

Three-dimensional plot of the illumination intensity distribution of two different scales CPC-PV cells: (a) the small-scale CPC-PV cell module; (b) the large-scale CPC-PV cell module. Both height and colour data represent illumination intensity.

Fig. 3(a) shows a three-dimensional plot of the non-uniform illumination intensity distribution of a small-scale CPC-PV cell module. It can be seen that the illumination intensity distribution of the whole cell is axisymmetric, which is caused by the symmetrical mirrors on both sides. Furthermore, the illumination intensity in the middle region of the cell is the lowest, and the illumination intensity is $1000 \mathrm{~W} / \mathrm{m}^{2}$. This is because when the ray is incident perpendicularly to the whole CPC-PV cell, there is almost no concentration in the middle region. There are two highest illumination intensity on both sides of the middle region, and the illumination intensity is $6800 \mathrm{~W} / \mathrm{m}^{2}$.

Fig. 3(b) shows a three-dimensional plot of the non-uniform illumination intensity distribution of a large-scale CPC-PV cell module. It can be seen that the illumination intensity distribution of the whole cell is asymmetrical. The illumination intensity of the right edge of the whole CPC-PV cell is the lowest, and the illumination intensity is $1000 \mathrm{~W} / \mathrm{m}^{2}$. The whole cell has a region of highest illumination intensity with an illumination intensity of $6800 \mathrm{~W} / \mathrm{m}^{2}$. This is because the whole cell only receives the ray of the left region of the CPC-PV cell module in Fig. 1(b). These two different scales CPC-PV cell modules have the same geometric concentration ratio. After numerical calculations, it can also be found that the total illumination 
intensity received by the two different scales CPC-PV cell modules is the same and the average illumination intensity of both is $3055 \mathrm{~W} / \mathrm{m}^{2}$.

\subsection{Mathematical modelling}

Since this study mainly deals with the problem of direct current flow in the conducting medium, the Partial Differential Equation (PDE) in the domain is the continuity equation [20,32]:

$$
-\nabla \cdot\left(\sigma \nabla V-J^{e}\right)=Q_{j}
$$

where $\mathrm{V}$ is the electric potential, $\mathrm{V} ; \mathrm{J}^{\mathrm{e}}$ is the current density, $\mathrm{Am}^{-2} ; Q_{j}$ is the current source term, $\mathrm{Am}^{-2}$; and $\sigma$ is the sheet conductivity of the material, $\Omega^{-1} \mathrm{~m}^{-1}$.

The conductivity of the emitter will be calculated from the experimentally obtainable sheet resistance $R_{\text {sheet }}$ by Ref. [33]:

$$
\sigma=\frac{1}{R_{\text {sheet }} t_{e}}
$$

where $t_{e}$ is the depth of the emitter, m.

The conductivity of the fingers will be calculated from the experimentally obtainable resistance per unit length $R_{L}$ by Ref. [8]:

$$
\sigma=\frac{1}{R_{L} W_{f} t_{f}}
$$

where $W_{f}$ is the finger width, $\mathrm{m}$ and $t_{f}$ is the finger depth, $\mathrm{m}$. There are similar considerations about the conductivity of bus-bar.

The current source $Q_{j}$ is interpreted to be generated in the cell volume by the diode including both photogenerated and reverse saturation currents. The PV cell characteristic curve model used was proposed by Ref. [ 34]. This allows obtaining parameter values that are independent of the size of the PV cell, thus allowing comparison with different PV cell types and sizes. For the same PV cell, the results can be discussed under different conditions. In the single diode model used, the recombination losses in the neutral and depletion regions are considered together. The description of the electrical parameterization indicates that the irradiance and temperature depend on several parameters of $I_{p h}, I_{0}, n V_{t h}$. The photocurrent generated $I_{p h}$ will increase slightly with a rise of temperature, which is mainly caused by greater diffusion lengths of the minority carriers and narrowing of the bandgap that displaces the absorption threshold towards the low energy photons [34]. 
The value of $I_{p h}$ is always small and can be ignored as an approximation. Thus, the $I_{p h}$ is considered to be proportional to the irradiance $\mathrm{G}: I_{p h}=C_{1} G$, where $C_{1}$ is a constant with respect to irradiance. The relationship between reverse saturation diode current and temperature can be written as follows [32]: $I_{0}=C_{2} T^{3} \exp \left(\frac{-E_{g}}{k_{b} T}\right)$, where $C_{2}$ and $E_{g}$ are both approximately constant with respect to temperature. Defining the diode voltage as $V_{j}=V+R_{s} I$, the generated current density for the illuminated regions can be described as follows:

$$
Q_{j}=C_{1} G+C_{2} T^{3} \exp \left(\frac{-E_{g}}{k_{b} T}\right)\left[\exp \left(\frac{q_{e} V_{j}}{n k_{b} T}\right)-1\right]+C_{3} V_{j}
$$

Similarly, the generated current density in the dark area under the busbar and finger regions is expressed by:

$$
Q_{j}=C_{2} T^{3} \exp \left(\frac{-E_{g}}{k_{b} T}\right)\left[\exp \left(\frac{q_{e} V_{j}}{n k_{b} T}\right)-1\right]+C_{3} V_{j}
$$

where $\mathrm{G}$ is the intensity of illumination, $\mathrm{W} / \mathrm{m}^{2}$; $\mathrm{T}$ is the cell junction temperature, $\mathrm{K}$; $\mathrm{E}_{\mathrm{g}}$ is the bandgap energy; $\mathrm{k}_{\mathrm{b}}$ is the Boltzmann constant; $\mathrm{q}_{\mathrm{e}}$ is the electron charge; $\mathrm{V}_{\mathrm{j}}$ is called the junction electric potential; $\mathrm{n}$ is the diode ideality factor; and $\mathrm{C}_{1}, \mathrm{C}_{2}$ and $\mathrm{C}_{3}$ are coefficients to a given cell (see Ref. [32] and reference therein).

\subsection{Boundary conditions}

Table 1 shows the specific boundary conditions applied in the model.

alt-text: Table 1

Table 1

(i) The presentation of Tables and the formatting of text in the online proof do not match the final output, though the data is the same. To preview the actual presentation, view the Proof.

Boundary conditions.

\section{Boundary \\ condition \\ Equation Description \\ identification}

\begin{tabular}{|l|l|l|}
\hline Interface condition & $-n_{b} \cdot\left(J_{1}-J_{2}\right)=0$ & $\begin{array}{l}\text { The interface conditions are applied to the entire cell model, to ensure the } \\
\text { continuity of the current flowing through all different media on all internal } \\
\text { boundaries }\end{array}$ \\
\hline Electrical & $n_{b} \cdot J=0$ & For the entire cell model, the outer boundary of finger section and emitter section
\end{tabular}




\begin{tabular}{|l|l|l|} 
insulation & are considered to be electrically insulated \\
\hline $\begin{array}{l}\text { Bus-bar electrical } \\
\text { potential }\end{array}$ & $V=V_{\text {cell }}$ & $\begin{array}{l}\text { The ends of bus-bar are considered to be connected to the external load and } \\
\text { should therefore have electrical potential equal to the cell operating voltage } V_{\text {cell }}\end{array}$ \\
\hline
\end{tabular}

\section{Model validation}

The CPC-PV cell of this study is tested under the Newport Corporation solar simulator (Oriel Sol3A Model 90943A). Firstly, the simulator can be set to produce an illumination intensity of $1000 \mathrm{~W} / \mathrm{m}^{2}$ (the uniform illumination difference is less than $2 \%$ in the $100 \times 100 \mathrm{~mm}^{2}$ illumination area produced by the simulator). Experimental data of the CPC-PV cell at an illumination intensity of $1000 \mathrm{~W} / \mathrm{m}^{2}$ can be obtained. Furthermore, the indoor ambient temperature is maintained at $298 \mathrm{~K}$. The detailed experimental test instrument setup is shown in Fig. 4. At last, through the simulator, the I-V curve of the CPC-PV cell and the parameters of the open circuit voltage $\left(V_{\text {oc }}\right)$, the short circuit current $\left(I_{s c}\right)$, the maximum power $\left(P_{\max }\right)$, the series resistance $\left(R_{s}\right)$, the shunt resistance $\left(R_{s h}\right)$ can be measured. The voltage measurement resolution is between $1 \mu \mathrm{V}$ and $1 \mathrm{mV}$, and the voltage source accuracy is $0.02 \%$. The current measurement resolution is between $100 \mathrm{pA}$ and $10 \mu \mathrm{A}$, and the current measurement accuracy is $0.05 \%$.

\section{alt-text: Fig. 4}

\section{Fig. 4}

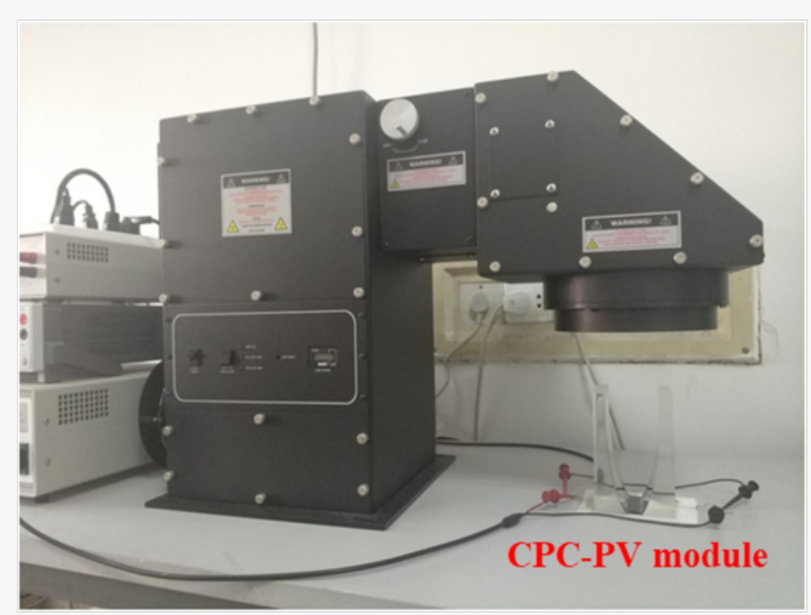

The experimental setup.

In order to verify the model, the experimental data of the CPC-PV cell was measured according to the laboratory experiment setup shown in Fig. 4. Then, the parameters used in the simulation are obtained based on the experimental data under standsrd test condition (STC). The specific parameter values used in the simulation are shown in Table 2. Fig. 5 shows the I-V and P-V curves of CPC-PV cell for the experiment and simulation. The experimental and simulation results are in good agreement, where the experimental and simulated open circuit voltage $\left(V_{\text {oc }}\right)$ and short circuit current $\left(I_{s c}\right)$ are almost identical. The maximum power value $\left(P_{\max }\right)$ of the experimental result is $0.406 \mathrm{~W}$, and the maximum power value of the simulation result is 
$0.425 \mathrm{~W}$. As shown in Fig. 5, there is a slight deviation in the consistency of two I-V curves around the maximum power point. The reason for this deviation is due to the fact that the cell model is placed under the ideal optical concentrator in the simulation, and there are various factors in the actual process leading to errors in the final results of the experiment. Moreover, for optical concentrators, the degradation of concentrator performance due to various errors is a common phenomenon. These errors have an effect on the optical performance of the concentrator. Therefore, it can be seen that the simulation results of the CPC-PV cell model in this study are basically consistent with the experimental results.

\section{alt-text: Table 2 \\ Table 2}

(i) The presentation of Tables and the formatting of text in the online proof do not match the final output, though the data is the same. To preview the actual presentation, view the Proof.

Input parameters used in all simulations.

Cell geometry and resistivities

Cell length (finger direction)

$7.0 \mathrm{~cm}$

Cell width (bus-bar direction)

$1.5 \mathrm{~cm}$

Bus-bar width

$2 \mathrm{~mm}$

Finger width

$20 \mu \mathrm{m}$

Finger resistance per unit length

$0.3 \Omega \mathrm{cm}^{-1}$

Emitter sheet resistance

$100 \Omega / \square$

Operation conditions

\begin{tabular}{l|l} 
Temperature & $298 \mathrm{~K}$ \\
\hline Mean illumination intensity & $3055 \mathrm{Wm}^{-2}$
\end{tabular}

Diode equation parameters

\begin{tabular}{|l|l|}
\hline$C_{1}$ & $0.294861 \mathrm{AW}^{-1}$ \\
\hline$C_{2}$ & $-2.51 \mathrm{E}+08 \mathrm{Am}^{-2} \mathrm{~K}^{-3}$ \\
\hline$C_{3}$ & $-8.400457 \mathrm{Am}^{-2} \mathrm{~V}^{-1}$ \\
\hline Ideality factor $n$ & 1.719499 \\
\hline$E_{g}$ & $1.124 \mathrm{eV}$ \\
\hline
\end{tabular}




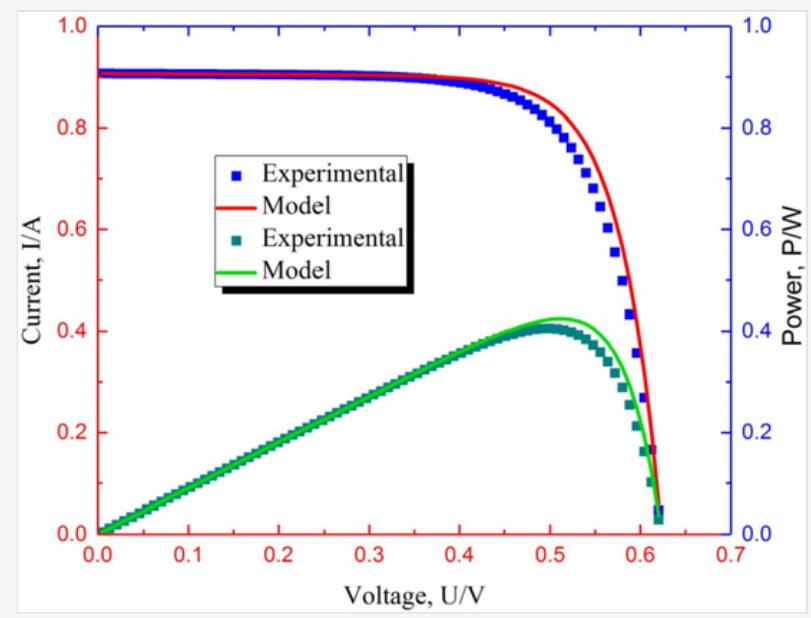

The small-scale CPC-PV cell module characteristic I-V and P-V curves for experiment and numerical model.

After determining the reliability of the model, two models of different scales CPC-PV cells were established. Through the analysis of the electrical performance of two different scales CPC-PV cells, the influence of different scales on the electrical performance of CPC-PV was finally determined.

\section{Results and discussion}

Based on the reliability of the validated CPC-PV cell model, two different scales CPC-PV cells were numerically simulated. The comparison of the electrical performance of the two different scales CPC-PV cells was carried out with the same temperature and the same total illumination intensity.

Fig. 6 shows the I-V curves of two different scales CPC-PV cell modules. The short circuit current and output power of a small-scale CPC-PV cell module are slightly higher than that of a large-scale CPC-PV cell module. The open circuit voltages of the two different scales CPC-PV cell modules are almost the same. This is due to the same temperature of the two different scales CPC-PV cell modules and the same total illumination intensity received.

alt-text: Fig. 6 


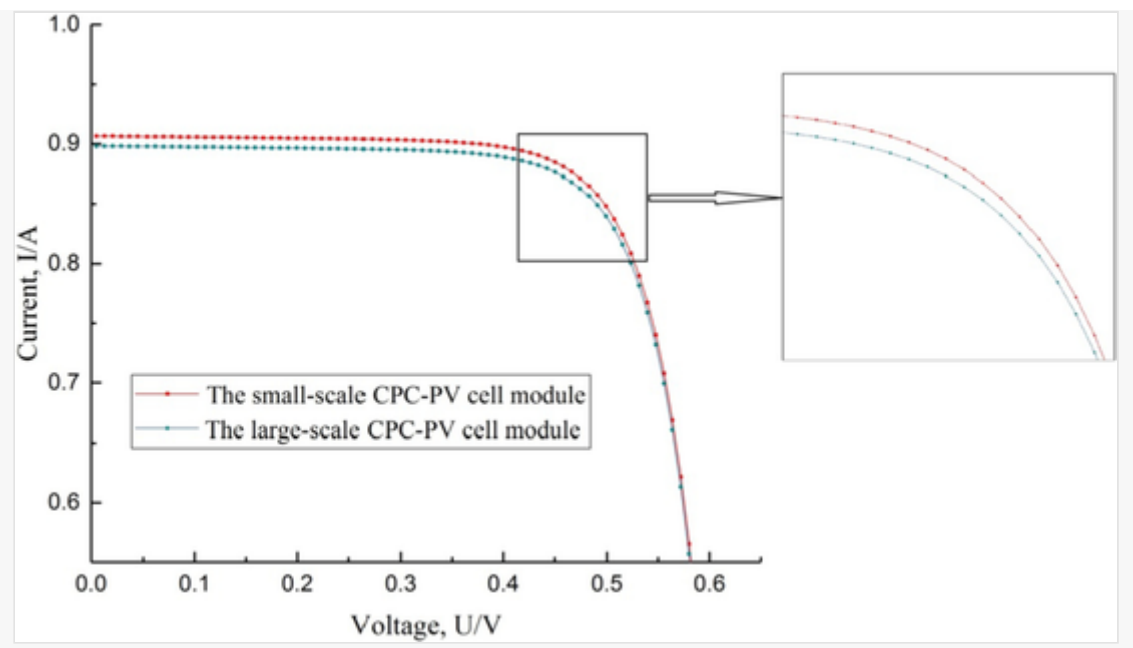

I-V curves for two different scales CPC-PV cell modules.

Table 3 gives the detailed electrical parameters of two different scales CPC-PV cell modules. It can be seen from the data that the efficiency of the small-scale CPC-PV cell is $13.248 \%$, and the efficiency of the largescale CPC-PV cell is $13.116 \%$. The electrical efficiency of small-scale CPC-PV cells is increased by $1.01 \%$ compared to large-scale CPC-PV cells. The maximum output power of a large-scale CPC-PV cells is $420.713 \mathrm{~mW}$, while the maximum output power of a small-scale CPC-PV cells is $424.960 \mathrm{~mW}$. This also indicates that the maximum output power of a small-scale CPC-PV cell is higher than that of a large-scale CPC-PV cell. It can be seen that although the scale of the two small-scale CPC-PV cells in Fig. 1(a) is the same as that of the complete CPC-PV cell in Fig. 1(b), the output power is increased by $1.01 \%$. That is, the use of a small-scale model for a CPC-PV cell with the same geometric concentration ratio will contribute to improving the electrical performance of the CPC-PV cell.

alt-text: Table 3

Table 3

(i) The presentation of Tables and the formatting of text in the online proof do not match the final output, though the data is the same. To preview the actual presentation, view the Proof.

Two different scales CPC-PV cell modules electrical parameters, $\mathrm{T}=298 \mathrm{~K}$ and $\mathrm{G}=3055 \mathrm{~W} / \mathrm{m}^{2}$.

\begin{tabular}{|c|c|c|}
\hline & The small-scale CPC-PV & The large-scale CPC-PV \\
\hline$I_{s c}(\mathrm{~A})$ & 0.906 & 0.898 \\
\hline$V_{o c}(\mathrm{~V})$ & 0.625 & 0.624 \\
\hline$P_{\max }(\mathrm{mW})$ & 424.960 & 420.713 \\
\hline$F F(\%)$ & 75.066 & 75.027 \\
\hline Efficiency $(\%)$ & 13.248 & 13.116 \\
\hline
\end{tabular}




\subsection{Current density distribution of two different scales CPC-PV cells}

Fig. 7 (a) shows a three-dimensional plot of the current density in the emitter of a small-scale CPC-PV cell. Since the illumination intensity is a factor that mainly affects the current density of the emitter region of the cell. According to the three-dimensional plot of the illumination intensity distribution shown in Fig. 3(a), it is known that there are two highest illumination intensity regions near the middle of the cell. Therefore, it can be seen from Fig. 7(a) that there are two higher current density regions near the middle of the cell, and the current density is $1.40 \mathrm{~A} / \mathrm{m}^{2}$. However, the highest current density regions in the entire current density distribution appears in the edge regions on the left and right sides, and the current density is $2.08 \mathrm{~A} / \mathrm{m}^{2}$. This is due to the fact that the current generated by the emitter regions can be quickly concentrated to the sides of the finger. The current generated in the emitter regions on the left and right sides, because the outermost edge of the cell is insulated, can only be concentrated into an internal finger. The current density in the regions near the finger on both sides of the cell is relatively high. Fig. 7(b) shows a three-dimensional plot of the current density in the emitter of a large-scale CPC-PV cell. It can be found that the region with the highest current density appears in the finger region on the left edge of the cell, and the current density is $2.19 \mathrm{~A} / \mathrm{m}^{2}$. This is because although the illumination intensity of the left edge regions of the large-scale CPC-PV cell and the small-scale CPC-PV cell is $3900 \mathrm{~W} / \mathrm{m}^{2}$, the corresponding large-scale CPC-PV cell has a larger region of the left-side illumination intensity. Therefore, the current density near the finger region on the left edge of the large-scale CPC-PV cell is slightly higher.

alt-text: Fig. 7

Fig. 7 

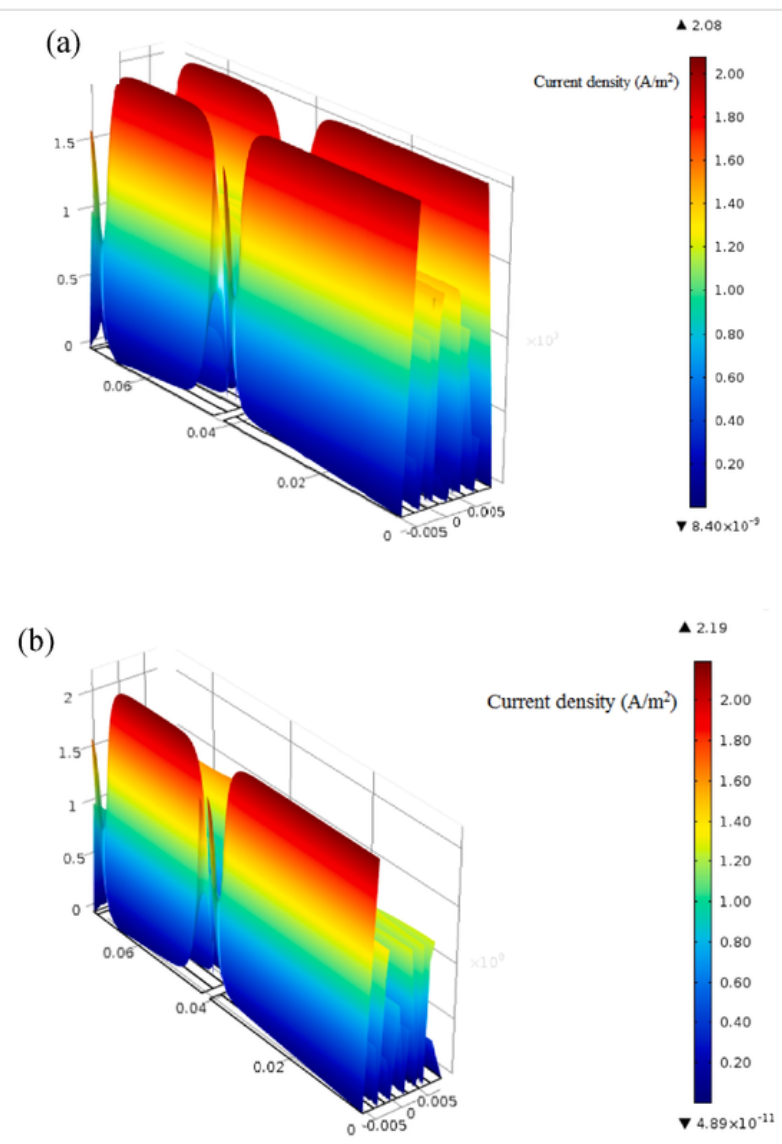

Three-dimensional plots of current density in the emitter of two different scales CPC-PV cells: (a) the small-scale CPC-PV cell module; (b) the large-scale CPC-PV cell module. Both height and colour data represent current density. Current density in the fingers and bus-bar is not plotted.

Comparing Fig. 7(a) with Fig. 7(b), it can be found that there are significant differences in the emitter regions current density distribution of the two different scales CPC-PV cells. This is because the overall illumination profile of small-scale CPC-PV cells and large-scale CPC-PV cells is different. The emitter resistance causes the junction voltage to increase with distance from the finger. Therefore, the region near the finger provides a higher current density for the output of the cell. Although the current density near the finger on the left side of the large-scale CPC-PV cell is relatively high, the lower current density distribution on the right side causes the current density on the right side of the large-scale CPC-PV cell to be significantly lower. Therefore, the output power of the small-scale CPC-PV cell is higher than that of the large-scale CPC-PV cell.

\subsection{Surface voltage distribution and internal current flow of two different scales CPC-PV cells}

Fig. 8 shows the surface voltage distribution and internal current flow of a small-scale CPC-PV cell. It can be seen from the surface voltage distribution given in Fig. 8(a) that the highest voltage is in the lower left and lower right regions of the cell with a highest voltage of $0.560 \mathrm{~V}$, the lowest voltage region is near the bus-bar with a lowest voltage of $0.516 \mathrm{~V}$. The internal current flow of the cell surface can be more clearly seen through Fig. 8(b), (c), and Fig. 8(d). The internal current generated by the emitter region of the cell mainly flows to the bus-bar through the nearby finger, and then flows to the outside of the cell. There is also a part of the internal 
current flowing directly from the emitter regions to the bus-bar, and then flows to the outside of the cell. For example, the black line in the emitter middle region of the cell in Fig. 8(b) (the black line indicates the internal current of the cell) and the red arrow (the red arrow is the direction of internal current flow of the cell).

alt-text: Fig. 8

\section{Fig. 8}

a

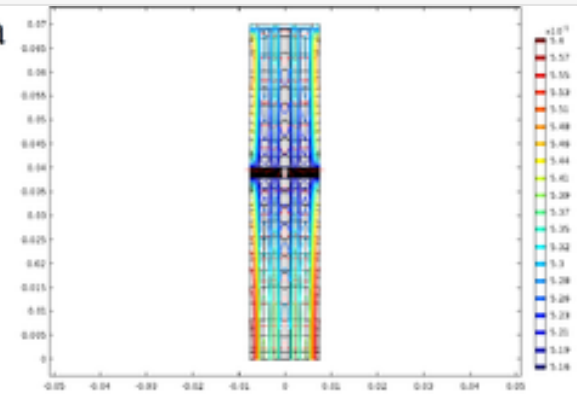

c

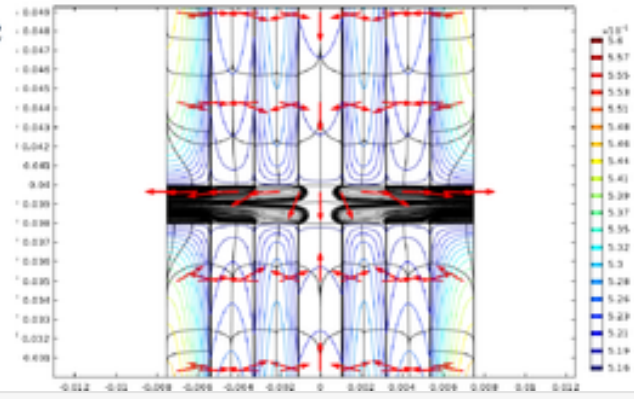

b

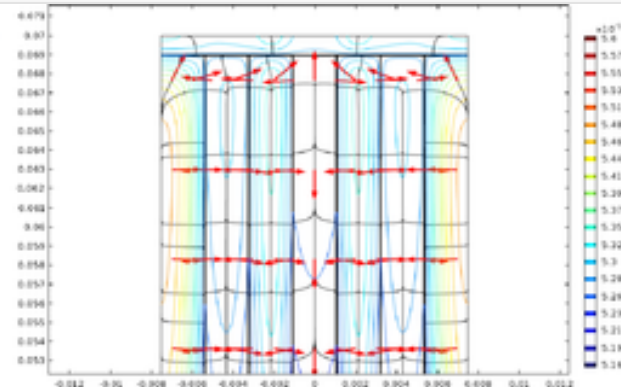

$\mathrm{d}$

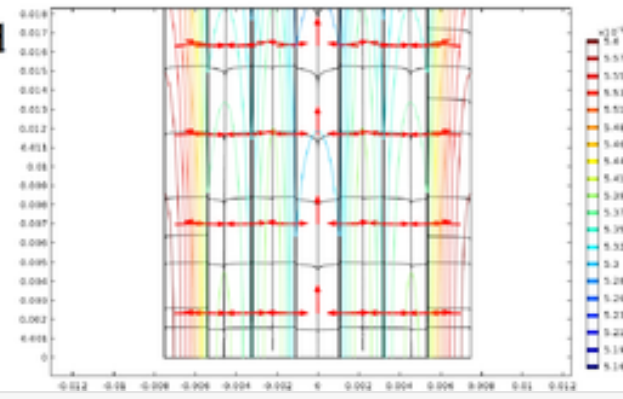

Voltage distribution and internal current flow of a small-scale CPC-PV cell: (a) voltage distribution and internal current flow of the whole cell; (b) voltage distribution and internal current flow in the region above the enlarged cell; (c) voltage distribution and current flow in the middle region of the enlarged cell; (d) voltage distribution and current flow in the region under the enlarged cell. The colored lines on the surface of the cell represent the voltage distribution contours, the black lines indicate internal current, and the red arrows indicate current flow directions.

Fig. 9 shows the surface voltage distribution and internal current flow of a large-scale CPC-PV cell. It can be seen from the surface voltage distribution given in Fig. 9(a) that the highest voltage is in the lower left region of the cell with a highest voltage of $0.563 \mathrm{~V}$, the lowest voltage region is near the bus-bar with a lowest voltage of $0.517 \mathrm{~V}$. The internal current flow of the cell surface can be seen more clearly by Fig. 9(b), (c), and Fig. 9 (d). The internal current generated by the emitter region of the cell mainly flows to the bus-bar through the nearby finger, and then flows to the outside of the cell. Due to the presence of the resistance of the finger and bus-bar, the internal current will have a certain current loss during the flow. Therefore, the comparison of the internal current flow processes of two different scales CPC-PV cells is beneficial to analyze the difference between the current losses of the two different scales CPC-PV cells.

alt-text: Fig. 9 


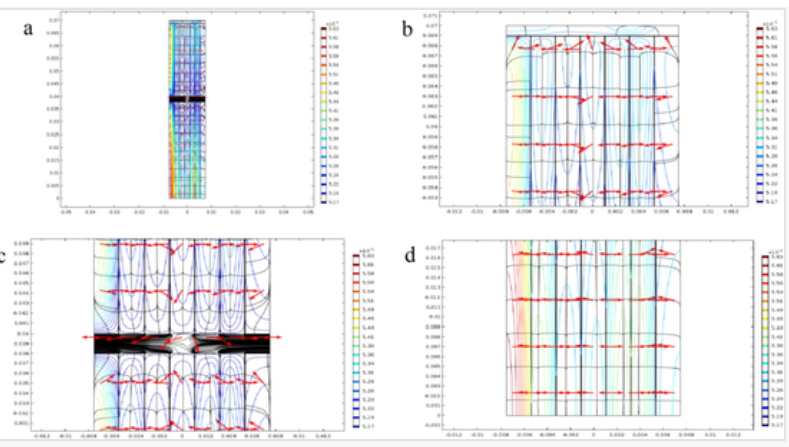

Voltage distribution and internal current flow of a large-scale CPC-PV cell: (a) voltage distribution and internal current flow of the whole cell; (b) voltage distribution and internal current flow in the region above the enlarged cell; (c) voltage distribution and current flow in the middle region of the enlarged cell; (d) voltage distribution and current flow in the region under the enlarged cell. The colored lines on the surface of the cell represent the voltage distribution contours, the black lines indicate internal current, and the red arrows indicate current flow directions.

It can be seen from Fig. 8 that the highest current density generated by the small-scale CPC-PV cell emitter region is gathered in the left and right regions of the cell, and the region with lowest current density is in the middle of the cell. It can be seen from Fig. 9 that the highest current density generated by the large-scale CPC$\mathrm{PV}$ cell emitter region is gathered in the left region of the cell, and the region with lowest current density is in the right of the cell. The internal currents on both sides of the cell flowing through the finger and bus-bar to the external load has less current loss than the internal current in the middle of the cell flowing through the finger and bus-bar to the external load. Therefore, by comparing two different scales CPC-PV cells, it is can be clearly seen that the current loss in the small-scale CPC-PV cell is relatively small during the flow of internal current from the emitter region to the external load. Thus, the electrical performance of the small-scale CPCPV cell is better than that of the large-scale CPC-PV cell.

\section{Conclusions}

The electrical performances of a small-scale CPC-PV cell module and a large-scale CPC-PV cell module of the same geometric concentration ratio were compared. The basis for the comparison of these two different scale CPC-PV cell modules is that the total illumination intensity of the whole cell is the same and the temperature remains constant.

Table 3 gives a comparison of the results of two different scale CPC-PV cell modules in this paper. It can be seen that the small-scale CPC-PV cell has better electrical performance. For the CPC-PV cells with the same geometric concentration ratio, the electrical efficiency of the small-scale CPC-PV cells is increased by $1.01 \%$ compared with that of the large-scale CPC-PV cells. This effect is largely due to the relatively small internal current loss of the small-scale CPC-PV cells, which has a relatively higher output power. By comparison, we can also see that the maximum output power of small-scale CPC-PV cells is $424.960 \mathrm{~mW}$, which is significantly higher than the maximum output power of large-scale CPC-PV cells of $420.713 \mathrm{~mW}$.

The research results show that smaller CPC-PV cells with the same geometric concentration ratio with that of larger CPC-PV cells will be beneficial to the improvement of electrical performance. When the geometric concentration ratio is the same, although the two CPC-PV cells of Fig. 1(a) and the complete CPC-PV cell of 
Fig. 1(b) are the same scale, the out power is increased by $1.01 \%$. This shows that by making the scale of a single CPC-PV cell smaller, the electrical efficiency and output power of the CPC-PV cell can be increased. For the CPC-PV cell market with larger applications, this research provides a feasible solution for improving the electrical performance of CPC-PV cells.where $\mathrm{n}_{\mathrm{b}}$ is the unit normal to the boundary; $\mathrm{J}_{1}$ and $\mathrm{J}_{2}$ are the current density vectors at the boundary of the adjacent media; and $\mathrm{J}$ is the current density vector at the external boundary.

\section{Acknowledgement}

This study was sponsored by the Project of EU Marie Curie International incoming Fellowships Program (745614). The authors would also like to express our appreciation for the financial supports from EPSRC (EP/R004684/1) and Innovate UK (TSB 70507-481546) for the Newton Fund - China-UK Research and Innovation Bridges Competition 2015 Project 'A High Efficiency, Low Cost and Building Integrate-able Solar Photovoltaic/Thermal (PV/T) system for Space Heating, Hot Water and Power Supply' and Dong Guan Innovation Research Team Program (No. 2014607101008).

\section{References}

The corrections made in this section will be reviewed and approved by journal production editor.

[1] Diallo TMO, Yu M, Zhou J, Zhao X, Shittu S, Li G, et al. Energy performance analysis of a novel solar PVT loop heat pipe employing a microchannel heat pipe evaporator and a PCM triple heat exchanger. Energy 2019;167:866-888.

[2] Shittu S, Li G, Zhao X, Ma X. Series of detail comparison and optimization of thermoelectric element geometry considering the PV effect. Renew Energy 2019;130:930-942.

[3] Li G, Shittu S, Diallo TMO, Yu M, Zhao X, Ji J. A review of solar photovoltaic-thermoelectric hybrid system for electricity generation. Energy 2018;158:41-58.

[4] Shittu S, Li G, Zhao X, Ma X, Akhlaghi YG, Ayodele E. High performance and thermal stress analysis of a segmented annular thermoelectric generator. Energy Convers Manag 2019; 184:180-193.

[5] Li G, Shittu S, Ma X, Zhao X. Comparative analysis of thermoelectric elements optimum geometry between Photovoltaic-thermoelectric and solar thermoelectric. Energy 2019;171:599610.

[6] Price JS, Grede AJ, Wang B, Lipski MV, Fisher B, Lee K-T, et al. High-concentration planar microtracking photovoltaic system exceeding 30\% efficiency. Nat Energy 2017;2:17113. 
Wang Z, Lin Q, Wenger B, Christoforo MG, Lin Y-H, Klug MT, et al. High irradiance performance of metal halide perovskites for concentrator photovoltaics. Nat Energy 2018;3:855861.

[8] Green MA, Emergy K, Hishikawa Y, Warta W, Dunlop ED. Solar cell efficiency tables (version 48). Prog Photovolt Res Appl 2016;24:905-913.

[9] Kil T-HH, Kim SS, Jeong D-HH, Geum D-MM, Lee S, Jung S-JJ, et al. A highly-efficient, concentrating-photovoltaic/thermoelectric hybrid generator. Nano Energy 2017;37:242-247.

[10] Hosenuzzaman M, Rahim NA, Selvaraj J, Hasanuzzaman M, Malek ABMA, Nahar A. Global prospects, progress, policies, and environmental impact of solar photovoltaic power generation. Renew Sustain Energy Rev 2015;41:284-297.

[11] Xing Y, Han P, Wang S, Liang P, Lou S, Zhang Y, et al. A review of concentrator silicon solar cells. Renew Sustain Energy Rev 2015;51:1697-1708.

[12] Sun Y, Wang Y, Zhu L, Yin B, Xiang H, Huang Q. Direct liquid-immersion cooling of concentrator silicon solar cells in a linear concentrating photovoltaic receiver. Energy 2014;65:264-271.

[13] Poulek V, Khudysh A, Libra M. Self powered solar tracker for Low Concentration PV (LCPV) systems. Sol Energy 2016;127:109-112.

[14] Amanlou Y, Tavakoli Hashjin T, Ghobadian B, Najafi G. Air cooling low concentrated photovoltaic/thermal (LCPV/T) solar collector to approach uniform temperature distribution on the PV plate. Appl Therm Eng 2018;141:413-421.

[15] Nilsson J, Håkansson H, Karlsson B. Electrical and thermal characterization of a PV-CPC hybrid. Sol Energy 2007;81:917-928.

[16] Tian M, Su Y, Zheng H, Pei G, Li G, Riffat S. A review on the recent research progress in the compound parabolic concentrator (CPC) for solar energy applications. Renew Sustain Energy Rev 2018;82:1272-1296.

[17] Li G. Design and development of a lens-walled compound parabolic concentrator-a review. J Therm Sci 2019;28(1):17-29.

[18] Lu W, Wu Y, Eames P. Design and development of a building façade integrated asymmetric compound parabolic photovoltaic concentrator (BFI-ACP-PV). Appl Energy 2018;220:325-336.

[19] Sabry M, Abdel-Hadi YA, Ghitas A. PV-integrated CPC for transparent façades. Energy Build 2013;66:480-484.

[20] Li G, Xuan Q, Lu Y, Pei G, Su Y, Ji J. Numerical and lab experiment study of a novel concentrating PV with uniform flux distribution. Sol Energy Mater Sol Cells 2018;179:1-9. 
[21] Hatwaambo S, Hakansson H, Nilsson J, Karlsson B. Angular characterization of low concentrating PV-CPC using low-cost reflectors. Sol Energy Mater Sol Cells 2008;92:13471351.

[22] Liu L, Jia Y, Lin Y, Alva G, Fang G. Numerical study of a novel miniature compound parabolic concentrating photovoltaic/thermal collector with microencapsulated phase change slurry. Energy Convers Manag 2017;153:106-114.

[23] Proell M, Osgyan P, Karrer H, Brabec CJ. Experimental efficiency of a low concentrating CPC PVT flat plate collector. Sol Energy 2017;147:463-469.

[24] Xuan Q, Li G, Pei G, Ji J, Su Y, Zhao B. Optimization design and performance analysis of a novel asymmetric compound parabolic concentrator with rotation angle for building application. Sol Energy 2017;158:808-818.

[25] Bahaidarah HM, Gandhidasan P, Baloch AAB, Tanweer B, Mahmood M. A comparative study on the effect of glazing and cooling for compound parabolic concentrator PV systems experimental and analytical investigations. Energy Convers Manag 2016;129:227-239.

[26] Bahaidarah HM, Tanweer B, Gandhidasan P, Ibrahim N, Rehman S. Experimental and numerical study on non-concentrating and symmetric unglazed compound parabolic photovoltaic concentration systems. Appl Energy 2014;136:527-536.

[27] Guiqiang L, Gang P, Yuehong S, Jie J, Riffat SB. Experiment and simulation study on the flux distribution of lens-walled compound parabolic concentrator compared with mirror compound parabolic concentrator. Energy 2013;58:398-403.

[28] Chen H, Zhang H, Li M, Liu H, Huang J. Experimental investigation of a novel LCPV/T system with micro-channel heat pipe array. Renew Energy 2018;115:773-782.

[29] Yu Y, Liu N, Li G, Tang R. Performance comparison of CPCs with and without exit angle restriction for concentrating radiation on solar cells. Appl Energy 2015;155:284-293.

[30] Tian M, Yu X, Su Y, Zheng H, Riffat S. A study on incorporation of transpired solar collector in a novel multifunctional PV/Thermal/Daylighting (PV/T/D) panel. Sol Energy 2018;165:90-99.

[31] Li G, Xuan Q, Pei G, Su Y, Lu Y, Ji J. Life-cycle assessment of a low-concentration PV module for building south wall integration in China. Appl Energy 2018;215:174-185.

[32] Mellor A, Domenech-Garret JL, Chemisana D, Rosell JI. A two-dimensional finite element model of front surface current flow in cells under non-uniform, concentrated illumination. Sol Energy 2009;83:1459-1465.

[33] Domenech-Garret JL. Cell behaviour under different non-uniform temperature and radiation combined profiles using a two dimensional finite element model. Sol Energy 2011;85:256-264. 
[34] Rosell JI, Ibáñez M. Modelling power output in photovoltaic modules for outdoor operating conditions. Energy Convers Manag 2006;47:2424-2430.

\section{Highlights}

- The model of a low-concentration PV module was verified by experiment.

- A comparison of two different scales low-concentration PV modules was made.

- The electrical characteristics of two scales low-concentration PVs were performed.

- The result shows that the small scale one has a better electrical performance.

\section{Queries and Answers}

Query: Your article is registered as a regular item and is being processed for inclusion in a regular issue of the journal. If this is NOT correct and your article belongs to a Special Issue/Collection please contact s.venkiteswaran@elsevier.com immediately prior to returning your corrections.

Answer: Yes

Query: Please confirm that given names and surnames have been identified correctly and are presented in the desired order and please carefully verify the spelling of all authors' names.

Answer: Yes

Query: Please confirm that the provided email "Guiqiang.Li@hull.ac.uk” is the correct address for official communication, else provide an alternate e-mail address to replace the existing one, because private e-mail addresses should not be used in articles as the address for communication.

Answer: Yes.

Query: Have we correctly interpreted the following funding source(s) and country names you cited in your article: EU Marie Curie International incoming Fellowships Program, United Kingdom; EPSRC, United Kingdom; Innovate UK, United Kingdom?

Answer: Yes 
